\title{
Successful Concomitant Therapy with Pirfenidone and Nintedanib in Idiopathic Pulmonary Fibrosis: A Case Report
}

\author{
Lars Hagmeyer Marcel Treml Christina Priegnitz Winfried J. Randerath \\ Clinic for Pneumology and Allergology, Center of Sleep Medicine and Respiratory Care, Bethanien Hospital, \\ Solingen, Germany
}

\section{Established Facts}

- Pirfenidone and nintedanib are two anti-fibrotic agents that have demonstrated therapeutic benefit, i.e. slowing disease progression, in patients with idiopathic pulmonary fibrosis (IPF).

- The therapeutic benefit of a concomitant therapy in IPF has not been previously evaluated, and there is no data regarding the safety and tolerability of concomitant pirfenidone and nintedanib treatment in Caucasian patients.

\section{Novel Insight}

- Concomitant treatment with pirfenidone and nintedanib appears to be a feasible treatment option and may show a substantial benefit in patients not responding to anti-fibrotic monotherapy with pirfenidone.

\section{Key Words}

Pirfenidone · Nintedanib · Concomitant treatment · Idiopathic pulmonary fibrosis

\begin{abstract}
Pirfenidone and nintedanib are both pleiotropic anti-fibrotic agents approved for the treatment of idiopathic pulmonary fibrosis (IPF) as monotherapy. To date, evidence supporting their efficacy as concomitant therapy has not been reported. Here, we present the first case of a Caucasian male patient with IPF treated with both pirfenidone and nintedanib following 2 years of treatment with pirfeni-
\end{abstract}

done monotherapy. Over a 24-month period, there was a clear decline in the patient's forced vital capacity from 3.5 liter before initiation of treatment to 2.5 liter after 24 months. Concomitant nintedanib treatment was initiated in March 2015. Lung function stabilized, and the two treatments were well tolerated. Treatment with pirfenidone and nintedanib has currently been ongoing for nearly 12 months. This is the first report of a successful long-term treatment with pirfenidone and nintedanib and suggests that in selected cases, concomitant anti-fibrotic therapy may represent a safe and therapeutically valuable escalation option after pirfenidone monotherapy.

(c) 2016 S. Karger AG, Basel

\section{KARGER}

E-Mail karger@karger.com

www.karger.com/res
C 2016 S. Karger AG, Basel

0025-7931/16/0914-0327\$39.50/0
Lars Hagmeyer

Bethanien Krankenhaus Solingen

Aufderhöher Strasse 169-175

DE-42699 Solingen (Germany)

E-Mail Lars.Hagmeyer@klinik-bethanien.de 


\section{Introduction}

Idiopathic pulmonary fibrosis (IPF) is a chronic, progressive lung disease characterised by progressive worsening of lung function and poor prognosis [1]. Recently, significant advances have been made in the treatment of this disease, and two different pleiotropic anti-fibrotic agents, pirfenidone (Roche Pharma AG, Grenzach, Germany) and nintedanib (Boehringer Ingelheim Pharma GmbH \& Co. KG, Ingelheim, Germany), have both received a conditional recommendation for use in patients with IPF [2] based on the results from large multi-centre studies demonstrating that they are effective at reducing lung function decline [3-5]. Both treatments are administered orally. Pirfenidone is a pyridone compound that has shown anti-fibrotic and anti-inflammatory effects in experimental studies. Although the exact molecular mechanism of action is unknown, pirfenidone inhibits fibroblast proliferation and blocks the production of profibrotic cytokines and extracellular matrix components that would otherwise lead to scarring of the lung [6-12]. Nintedanib, an indolinone derivative, is a tyrosine kinase inhibitor that targets multiple tyrosine kinases, including vascular endothelial growth factor receptor, fibroblast growth factor receptor, and platelet-derived growth factor receptor); these receptors are known to be involved in the pathogenesis of IPF. Nintedanib has been shown to inhibit intracellular signalling pathways involved in fibroblast proliferation, migration and differentiation, and collagen synthesis and has demonstrated anti-fibrotic and anti-inflammatory activity in animal models of pulmonary fibrosis $[13,14]$. Recent data from in vitro studies suggest that the combination of pirfenidone and nintedanib might provide enhanced efficacy by suppressing the proliferation of fibroblastic cells; combination treatment reduced in vitro proliferation of stromal cells more than either agent alone [15].

The safety, tolerability and pharmacokinetics of concomitant therapy with pirfenidone and nintedanib have previously been evaluated in Japanese patients with IPF in a randomised, double-blind phase II study in which 21 of 50 randomised patients were treated with concomitant therapy [16]; only 9 patients receiving pirfenidone and nintedanib at the full recommended dosage. The followup periods were 14 days in two cohorts and 28 days in one cohort. This trial showed that the addition of nintedanib to chronic background pirfenidone treatment resulted in a trend to lower nintedanib plasma levels, but there was no effect on the pharmacokinetics of pirfenidone. Gastrointestinal toxicity was the most common adverse event

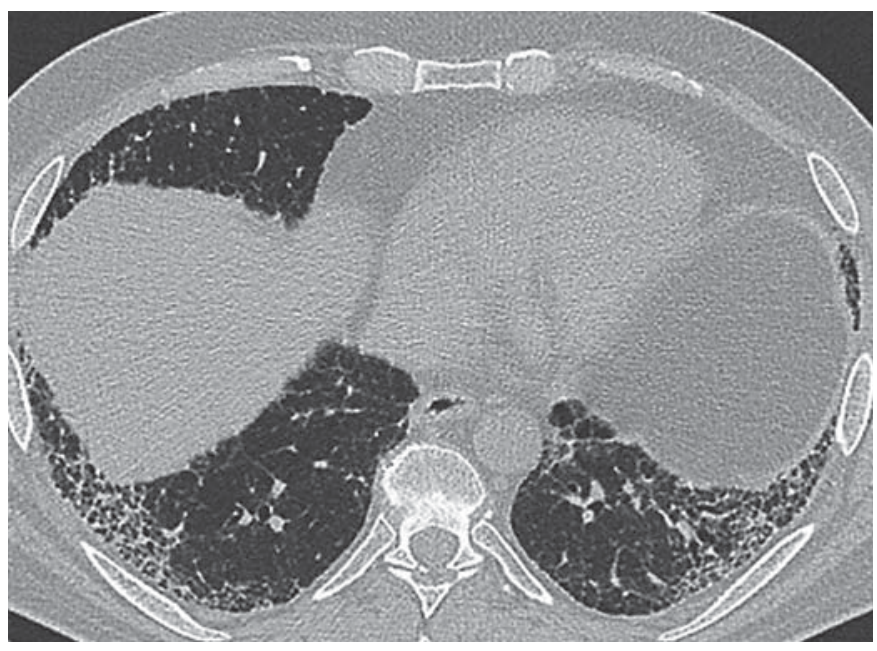

Fig. 1. High-resolution computed tomography scan at the time of diagnosis.

and seemed to be more frequent with concomitant treatment. To date, the tolerability and efficacy of this combination in non-Asian patients with IPF has not been investigated nor has the efficacy of concomitant therapy with pirfenidone and nintedanib in any population; the short duration and low patient numbers included in the Japanese trial meant that conclusions regarding the efficacy of concomitant treatment could not be made. Further evaluation of this combination is needed to establish the efficacy of concurrent use of two anti-fibrotic agents in reducing decline in lung function and to determine whether gastrointestinal adverse events can be effectively managed.

Here, we report the case of a Caucasian patient successfully treated with pirfenidone and nintedanib following disease progression with pirfenidone monotherapy.

\section{Case Report}

A 63-year-old male Caucasian patient had been diagnosed with IPF in March 2013 and began treatment with pirfenidone. A highresolution computed tomography scan at the time of diagnosis is shown in figure 1. Treatment was initiated using the standard dose titration schedule over 14 days, and the patient continued to receive the recommended dose of 2,403 $\mathrm{mg} /$ day split over 3 equal doses. Treatment was generally well tolerated, and compliance was good; however, over a 24-month period there was a clear decline in the patient's forced vital capacity from 3.5 liter before initiation of treatment to 2.5 liter after 24 months (26\% absolute reduction). This was accompanied by a $16 \%$ reduction in the diffusing capacity of the lung for carbon monoxide (fig. 2). 


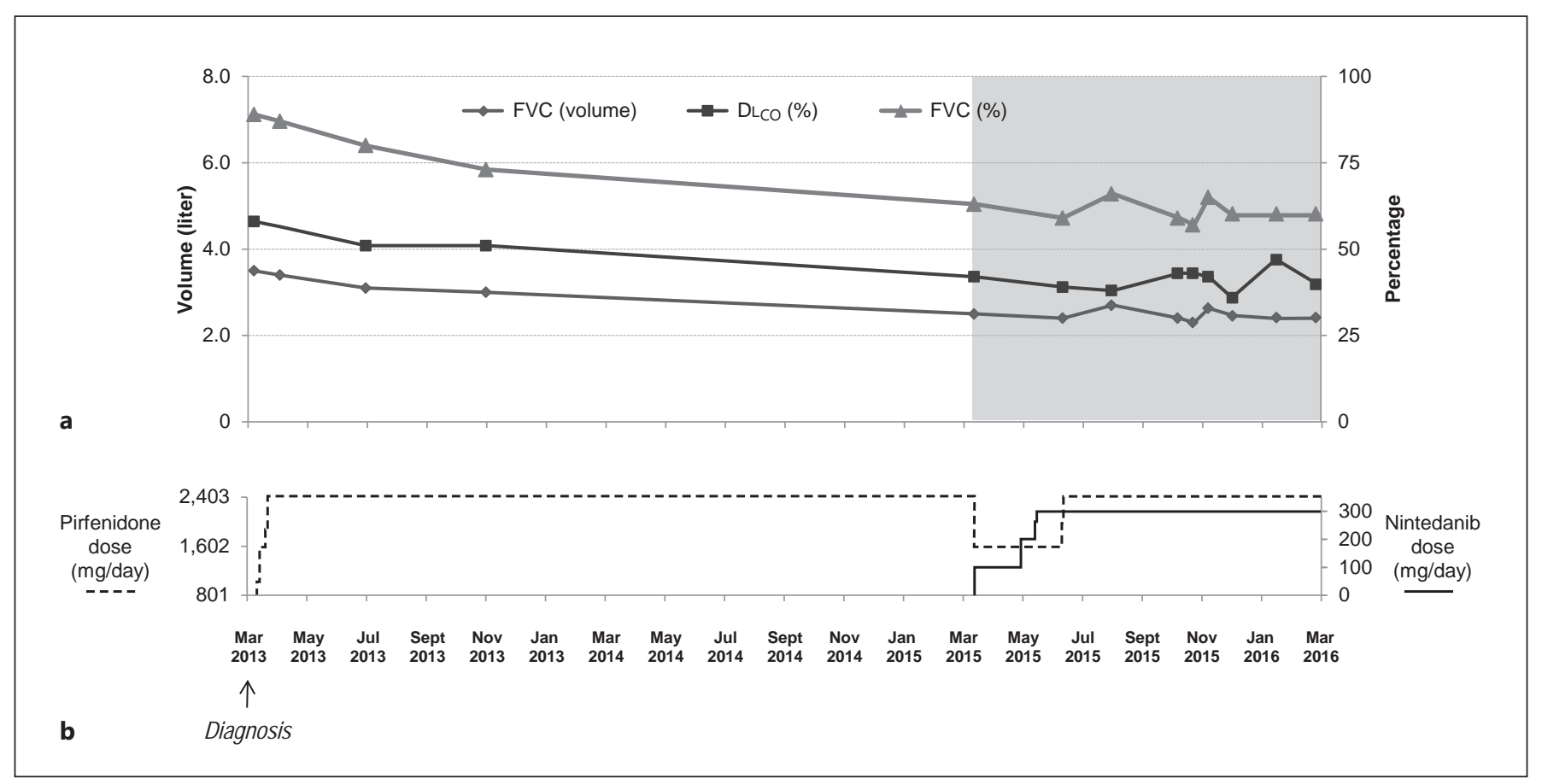

Fig. 2. Lung function (a) and dosing with pirfenidone alone and then concomitant treatment with pirfenidone plus nintedanib (b). FVC = Forced vital capacity; FVC (\%) = percentage of the predicted forced vital capacity; DLCO $(\%)=$ percentage of the diffusing capacity of the lung for carbon monoxide.

Table 1. Dosing and administration schedule for pirfenidone alone and then concomitant treatment with pirfenidone plus nintedanib

\begin{tabular}{|c|c|c|c|c|c|c|c|}
\hline \multirow[t]{3}{*}{ Date } & \multicolumn{4}{|c|}{ Pirfenidone dosing } & \multicolumn{3}{|c|}{ Nintedanib dosing } \\
\hline & \multicolumn{3}{|l|}{ time } & \multirow[t]{2}{*}{ total/day } & \multicolumn{2}{|l|}{ time } & \multirow[t]{2}{*}{ total/day } \\
\hline & 7 a.m. & 3 p.m. & 11 p.m. & & a.m. & p.m. & \\
\hline 6-12 March 2013 & 267 & 267 & 267 & 801 & & & \\
\hline 13-20 March 2013 & 534 & 534 & 534 & 1,602 & & & \\
\hline 21 March 2013-12 March 2015 & 801 & 801 & 801 & 2,403 & & & \\
\hline 13 March-29 April 2015 & 534 & 534 & 534 & 1,602 & $7: 00 ; 100$ & $7: 00 ; 0$ & 100 \\
\hline 30 April-14 May 2015 & 534 & 534 & 534 & 1,602 & $7: 00 ; 100$ & $7: 00 ; 100$ & 200 \\
\hline 15 May-10 June 2015 & 534 & 534 & 534 & 1,602 & $7: 00 ; 150$ & $7: 00 ; 150$ & 300 \\
\hline 11 June-31 July 2015 & 801 & 801 & 801 & 2,403 & $7: 00 ; 150$ & $7: 00 ; 150$ & 300 \\
\hline 1 August 2015 to date & 801 & 801 & 801 & 2,403 & $9: 00 ; 150$ & $9: 00 ; 150$ & 300 \\
\hline
\end{tabular}

Pirfenidone and nintedanib dosing is given in $\mathrm{mg}$.

In March 2015, the patient was offered treatment with nintedanib but was reluctant to discontinue treatment with pirfenidone. As such, add-on treatment with nintedanib was initiated. The dosage and administration schedule of both agents is shown in table 1 . Due to the limited data on concomitant medication use and expected adverse events, careful dose titration of nintedanib was conducted over a 12 -week period up to the full recommended daily dose of $150 \mathrm{mg}$ nintedanib every $12 \mathrm{~h}$. As data from the
Japanese study [16] suggested that there may be a concern for hepatotoxicity, the dose of pirfenidone was reduced when nintedanib was initiated in case of cumulative toxic effects on plasma levels. Following discussion with the patient, dose increases were conducted slowly as the patient was unable to attend hospital visits every 7 to 14 days. Since June 2015, the patient has been receiving both pirfenidone and nintedanib at the full recommended daily dose. 
Treatment with pirfenidone and nintedanib has currently been ongoing for nearly 12 months (from March 2015 to February 2016) with good tolerability and no long-lasting adverse events. Over this period of concomitant therapy, the patient has experienced 3 episodes of vomiting that occurred in the morning following simultaneous intake of both medications. As vomiting was infrequent, the patient was reluctant to take concomitant medication to control vomiting. As such, all episodes of vomiting were effectively managed by avoiding simultaneous intake of both medications. At the start of concomitant therapy, both medications were taken at 7 a.m. From August 1, 2015, the morning dose of pirfenidone was taken at 7 a.m., and the morning dose of nintedanib at 9 a.m. This reduced the vomiting to occasional, mild nausea the patient was able to tolerate. Weight loss, an adverse event reported with both agents, was not observed. The patient's body weight was $84 \mathrm{~kg}$ at diagnosis and $86 \mathrm{~kg}$ at the start of concomitant therapy. On November 6,2015 , the patient weighed $83 \mathrm{~kg}$. Laboratory evaluations indicate that the patient has not experienced any abnormalities in haematological parameters with concomitant therapy, and normal liver parameters (aspartate transaminase, alanine transaminase, $\gamma$-glutamyltransferase, alkaline phosphatase, and bilirubin) have been observed. Compliance with both pirfenidone and nintedanib therapy has been good, and dose reductions or treatment interruptions of either medication have not been necessary. Of importance for the patient, lung function assessments have shown stabilisation of lung function for the first time, as indicated by forced vital capacity and diffusing capacity of the lung for carbon monoxide parameters (fig. 2). Treatment with both pirfenidone and nintedanib is currently ongoing with the last visit on February 24, 2016. The patient had a viral lung infection over the period from December 2015 to January 2016.

\section{Discussion}

To our knowledge, this case represents the first report of successful long-term treatment of IPF with concomitant therapy using pirfenidone and nintedanib in a patient with progressive decline of lung volume with pirfenidone monotherapy. While both pirfenidone and nintedanib monotherapy have been shown to be effective in reducing functional decline and disease progression in IPF and have revolutionised the treatment of this progressive disease, they do not represent a cure, and patients may continue to deteriorate despite treatment. To date, there is little evidence to guide treatment choice after initial pirfenidone or nintedanib monotherapy. Similar to other chronic respiratory diseases, combination treatment is an obvious treatment option especially given that both agents have distinct mechanisms of action and show different pharmacological properties. Our case illustrates that the addition of nintedanib to pirfenidone therapy can result in the stabilisation of previously progressive disease with established anti-fibrotic agents and that improvements can be maintained for at least 11 months.
While previous data reports that short-term concomitant administration of both agents had an acceptable safety and tolerability profile, the efficacy of this treatment was not evaluated [16].

Nausea and vomiting were the only adverse events experienced by the patient and occurred only following simultaneous morning administration of both substances. It is not unexpected that the patient experienced gastrointestinal adverse events given that these are among the most common adverse events experienced with both agents when given as monotherapy. In the phase III ASCEND trial, pirfenidone was more commonly associated with adverse events in the upper gastrointestinal tract than placebo, including nausea (36 vs. 13\%), dyspepsia (18 vs. $6 \%$ ), vomiting (13 vs. $9 \%$ ), and gastroesophageal reflux (12 vs. $7 \%)$. These events were generally reversible and rarely led to discontinuation [3]. Similarly, in the phase III INPULSIS- 1 and INPULSIS- 2 studies, the adverse events related to the upper gastrointestinal tract that were more commonly reported with nintedanib compared with placebo but were manageable [5] were nausea (INPULSIS-1: 23 vs. $6 \%$; INPULSIS-2: 26 vs. $7 \%$ ) and vomiting (INPULSIS-1: 13 vs. $2 \%$; INPULSIS-2: 10 vs. $3 \%$ ). Of note, diarrhoea was the most commonly reported adverse event with nintedanib treatment (INPULSIS-1: 62 vs. 19\%; INPULSIS-2: 63 vs. $18 \%$ ), although this rarely led to treatment discontinuations $(<5 \%$ of all cases in the nintedanib arm). Compared to previous data suggesting that adverse events related to the upper gastrointestinal tract seemed to be more frequent with concomitant pirfenidone and nintedanib treatment [16], our case suggests that cumulative toxicity can be avoided and symptoms can be effectively managed by taking the medications at different times. Of note, no pharmacokinetic data was available from our patient to assess potential drug-drug interactions; this should be considered a limitation. An additional limitation is that the current duration of concomitant therapy using pirfenidone and nintedanib (nearly 12 months) is shorter than the previous duration of pirfenidone monotherapy ( 2 years); thus, it is uncertain whether the observed reduction in lung function decline currently observed will be maintained for the long term.

Findings from this single case report, combined with data from a phase II study in Japanese patients, support further investigation of the concomitant therapy with pirfenidone and nintedanib for the treatment of IPF. Central to the design of these trials will be the ability to determine whether the incremental benefit of concomitant therapy is the result of combination treatment or solely due to the 
addition of a new anti-fibrotic agent; a benefit that could also be achieved by switching from pirfenidone to nintedanib. It should be considered that we cannot rule out that our patient may have benefitted equally from a switch from pirfenidone to nintedanib. Nevertheless, against the backdrop of poor prognosis in IPF and the limited effectiveness of available single agents, concomitant therapy represents an attractive theoretical treatment approach that warrants further investigation. Indeed, the routine clinical management of other rare lung diseases, such as pulmonary arterial hypertension and pulmonary manifestations of autoimmune diseases, has shifted from monotherapy towards combination therapy [17-20]. Furthermore, numerous agents are currently being investigated in prospective studies for the treatment of IPF, and new combinations will be possible as new agents are approved for use.

In conclusion, the presented case study indicates that concomitant anti-fibrotic therapy with pirfenidone and nintedanib is well tolerated and can be effective for the management of mild-to-moderate IPF. In the patient with progressive decline in lung function during monotherapy with pirfenidone presented herein, stabilisation of lung function was achieved using treatment with both pirfenidone and nintedanib. Due to the lack of sufficient efficacy and safety data, concomitant treatment cannot currently be routinely recommended, although further studies of this combination are warranted. Indeed, two studies are currently planned or ongoing to further investigate the safety and tolerability of concomitant therapy $[21,22]$. Future studies should also be conducted to determine the relative benefits of concomitant therapy compared to switching from pirfenidone monotherapy to nintedanib monotherapy.

\section{Acknowledgements}

Editorial assistance, supported financially by Boehringer Ingelheim, was provided by Suzanne Patel during the preparation of the manuscript.

\section{Disclosure Statement}

L.H. and W.J.R. have received consulting and speaking honoraria from Boehringer Ingelheim and Roche.

\section{References}

1 Poletti V, Ravaglia C, Buccioli M, Tantalocco P, Piciucchi S, Dubini A, Carloni A, Chilosi M, Tomassetti S: Idiopathic pulmonary fibrosis: diagnosis and prognostic evaluation. Respiration 2013;86:5-12

2 Raghu G, Rochwerg B, Zhang Y, Garcia CA, Azuma A, Behr J, Brozek JL, Collard HR, Cunningham W, Homma S, Johkoh T, Martinez FJ, Myers J, Protzko SL, Richeldi L, Rind D, Selman M, et al: An official ATS/ERS/JRS/ ALAT Clinical Practice Guideline: treatment of idiopathic pulmonary fibrosis. An update of the 2011 clinical practice guideline. Am J Respir Crit Care Med 2015;192:e3-e19.

-3 King TE Jr, Bradford WZ, Castro-Bernardini S, Fagan EA, Glaspole I, Glassberg MK, Gorina E, Hopkins PM, Kardatzke D, Lancaster L, Lederer DJ, Nathan SD, Pereira CA, Sahn SA, Sussman R, Swigris JJ, Noble PW, Group AS: A phase 3 trial of pirfenidone in patients with idiopathic pulmonary fibrosis. N Engl J Med 2014;370:2083-2092.

4 Noble PW, Albera C, Bradford WZ, Costabel U, Glassberg MK, Kardatzke D, King TE Jr, Lancaster L, Sahn SA, Szwarcberg J, Valeyre $\mathrm{D}$, du Bois RM, Group CS: Pirfenidone in patients with idiopathic pulmonary fibrosis (capacity): two randomised trials. Lancet 2011; 377:1760-1769.
5 Richeldi L, du Bois RM, Raghu G, Azuma A, Brown KK, Costabel U, Cottin V, Flaherty KR, Hansell DM, Inoue Y, Kim DS, Kolb M, Nicholson AG, Noble PW, Selman M, Taniguchi H, Brun M, Le Maulf F, Girard M, Stowasser S, Schlenker-Herceg R, Disse B, Collard HR, INPULSIS Trial Investigators: Efficacy and safety of nintedanib in idiopathic pulmonary fibrosis. N Engl J Med 2014;370: 2071-2082.

-6 Iyer SN, Gurujeyalakshmi G, Giri SN: Effects of pirfenidone on transforming growth factor-beta gene expression at the transcriptional level in bleomycin hamster model of lung fibrosis. J Pharmacol Exp Ther 1999;291:367373.

7 Iyer SN, Gurujeyalakshmi G, Giri SN: Effects of pirfenidone on procollagen gene expression at the transcriptional level in bleomycin hamster model of lung fibrosis. J Pharmacol Exp Ther 1999;289:211-218.

8 Oku H, Shimizu T, Kawabata T, Nagira M, Hikita I, Ueyama A, Matsushima S, Torii M, Arimura A: Antifibrotic action of pirfenidone and prednisolone: different effects on pulmonary cytokines and growth factors in bleomycin-induced murine pulmonary fibrosis. Eur J Pharmacol 2008;590:400-408.
99 Grattendick KJ, Nakashima JM, Feng L, Giri SN, Margolin SB: Effects of three anti-TNFalpha drugs: Etanercept, infliximab and pirfenidone on release of TNF-alpha in medium and TNF-alpha associated with the cell in vitro. Int Immunopharmacol 2008;8:679-687.

10 Lee BS, Margolin SB, Nowak RA: Pirfenidone: a novel pharmacological agent that inhibits leiomyoma cell proliferation and collagen production. J Clin Endocrinol Metab 1998;83: 219-223.

11 Iyer SN, Wild JS, Schiedt MJ, Hyde DM, Margolin SB, Giri SN: Dietary intake of pirfenidone ameliorates bleomycin-induced lung fibrosis in hamsters. J Lab Clin Med 1995; 125: 779-785.

12 Schelegle ES, Mansoor JK, Giri S: Pirfenidone attenuates bleomycin-induced changes in pulmonary functions in hamsters. Proc Soc Exp Biol Med 1997;216:392-397.

13 Wollin L, Maillet I, Quesniaux V, Holweg A, Ryffel B: Antifibrotic and anti-inflammatory activity of the tyrosine kinase inhibitor nintedanib in experimental models of lung fibrosis. J Pharmacol Exp Ther 2014;349:209-220.

14 Wollin L, Wex E, Pautsch A, Schnapp G, Hostettler KE, Stowasser S, Kolb M: Mode of action of nintedanib in the treatment of idiopathic pulmonary fibrosis. Eur Respir J 2015; 45:1434-1445. 
15 Lehtonen ST, Veijola A, Karvonen H, LappiBlanco E, Sormunen R, Korpela S, Zagai U, Sköld MC, Kaarteenaho R: Pirfenidone and nintedanib modulate properties of fibroblasts and myofibroblasts in idiopathic pulmonary fibrosis. Respir Res 2016;17:14.

16 Ogura T, Taniguchi H, Azuma A, Inoue Y, Kondoh Y, Hasegawa Y, Bando M, Abe S, Mochizuki Y, Chida K, Kluglich M, Fujimoto T, Okazaki K, Tadayasu Y, Sakamoto W, Sugiyama Y: Safety and pharmacokinetics of nintedanib and pirfenidone in idiopathic pulmonary fibrosis. Eur Respir J 2015;45:13821392.

17 Galie N, Barbera JA, Frost AE, Ghofrani HA, Hoeper MM, McLaughlin VV, Peacock AJ,
Simonneau G, Vachiery JL, Grunig E, Oudiz RJ, Vonk-Noordegraaf A, White RJ, Blair C, Gillies H, Miller KL, Harris JH, Langley J, Rubin LJ, AMBITION Investigators: Initial use of ambrisentan plus tadalafil in pulmonary arterial hypertension. N Engl J Med 2015;373: 834-844.

18 Ghofrani HA, Humbert M: The role of combination therapy in managing pulmonary arterial hypertension. Eur Respir Rev 2014;23: 469-475.

19 Walker KM, Pope J; participating members of the Scleroderma Clinical Trials Consortium (SCTC); Canadian Scleroderma Research Group: Treatment of systemic sclerosis complications: what to use when first-line treat- ment fails - a consensus of systemic sclerosis experts. Semin Arthritis Rheum 2012;42:4255.

20 Antoniou KM, Symvoulakis EK, Anyfantakis D, Wells AU: New treatments for idiopathic pulmonary fibrosis: 'die another day' if diagnosed early? Respiration 2015;90:352-352.

21 Safety, tolerability and PK of nintedanib in combination with pirfenidone in IPF. https:// wwwclinicaltrialsgov/ct $2 /$ show / NCT02579603.

22 Safety and tolerability study of pirfenidone in combination with nintedanib in participants with idiopathic pulmonary fibrosis (IPF). https://wwwclinicaltrialsgov/ct2/show/ NCT02598193. 